\title{
Elementos estructurales y coyunturales de una implementación conflictiva del Acuerdo de Paz entre el Gobierno colombiano y las FARC-EP*
}

\author{
Beatriz Tiusabá Gómez (Colombia)** \\ Cristian López (Colombia) ${ }^{* * *}$
}

\section{Resumen}

Tras la firma del Acuerdo final para la terminación del conflicto y la construcción de una paz estable y duradera entre las FARC-EP y el Estado colombiano se inició un proceso de implementación conflictiva, derivado de realidades de orden estructural y coyuntural. Dicha conflictividad ha sido consecuencia de limitaciones propias de un proceso de negociación que no se planteó la superación de las causas estructurales que originaron el conflicto y que se desenvolvió con un compromiso diferencial de los actores. Desde de una metodología históricodescriptiva, con la intención de evidenciar el proceso de implementación del acuerdo y las complejidades que el proceso contrajo, este artículo analiza el primer año de implementación del Acuerdo y su carácter conflictivo a partir de categorías como la formación del Estado-Nación en Colombia, la refrendación del Acuerdo y el papel de las ramas del poder público en el proceso de su implementación efectiva.

\section{Palabras clave}

Negociaciones de Paz; Conflicto Armado; Posconflicto; Conflicto Político; Colombia.

Fecha de recepción: mayo de 2018 • Fecha de aprobación: noviembre de 2018

\footnotetext{
*Este artículo es producto del proyecto de investigación INV_EES_2587, El proceso de construcción de Estado en Colombia mediado por el conflicto armado interno. Los gobiernos de Álvaro Uribe y Juan Manuel Santos (2002-2017): ¿un proceso diferenciado?, financiado por la Vicerrectoría de Investigaciones de la Universidad Militar Nueva Granada. Agradecemos la colaboración, contribuciones y apoyo al equipo del proyecto de investigación al que está adscrito este artículo.

${ }_{* *}^{*}$ Politóloga. Magíster en Relaciones y Negocios Internacionales. Docente de tiempo completo e investigadora de la Facultad de Relaciones Internacionales, Seguridad y Estrategia, Universidad Militar Nueva Granada, Colombia. Correo electrónico: beatriz.tiusaba@unimilitar.edu.co - Orcid: https://orcid.org/0000-0001-5351-947X

*** Politólogo. Asistente de investigación del proyecto INV_EES_2587, Facultad de Relaciones Internacionales, Seguridad y Estrategia, Universidad Militar Nueva Granada, Colombia. Correo electrónico: cristian.unal@gmail.com
} 


\title{
Cómo citar este artículo
}

Tiusabá Gómez, Beatriz y López, Cristian. (2019). Elementos estructurales y coyunturales de una implementación conflictiva del Acuerdo de Paz entre el Gobierno colombiano y las FARC-EP. Estudios Políticos (Universidad de Antioquia), 55, pp. 224-244. http://doi.org/10.17533/udea.espo.n55a11

\section{Structural and Conjunctural Elements of a Conflicting Implementation of the Peace Agreement between the Colombian Government and the FARC-EP}

\begin{abstract}
After the signature of the Final Agreement to End the Armed Conflict and Build a Stable and Lasting Peace, began the process of a very conflictive implementation caused by structural and conjunctural problems. On the one hand, the negotiation process did not approached the structural reasons that originated the conflict, that is, the continuity of social, political, and economic conflicts; on the other hand, there was a difference in the level of commitment by the actors. This article analyzes the conflictual implementation from different categories, as the conformation of the Colombian Nation-State, the endorsement of the Agreement, and the role played by the branches of public power in the implementation. The study is based on a historical-descriptive methodology with the aim of evidencing the process of the agreement and the complexities faced in its implementation.
\end{abstract}

\section{Keywords}

Peace Negotiations; Armed Conflict; Post-Conflict; Political Conflict; Colombia. 


\section{Introducción}

Este artículo analiza el primer año de implementación del Acuerdo final para la terminación del conflicto y la construcción de una paz estable y duradera entre el Gobierno nacional y las FARC-EP (24 de noviembre de 2016) —en adelante Acuerdo de Paz-. Dicho análisis no hace énfasis en sucesos o hechos cronológicamente dispuestos, sino en el carácter conflictivo que ha tenido la implementación a partir de la revisión de diferentes tensiones de orden estructural y coyuntural que la han marcado.

La hipótesis central es que la implementación del Acuerdo de Paz es un proceso conflictivo, en primer lugar, porque constituye un nuevo escenario donde tiene continuidad un conflicto político, económico y social irresuelto; en segundo lugar, porque la firma del Acuerdo que se busca implementar no garantiza la superación de las causas estructurales que alimentaron el conflicto; ${ }^{1}$ y en tercer lugar, por el compromiso diferenciado de que han tenido los actores con la implementación.

Es preciso señalar que la caracterización que se hace de la implementación del Acuerdo de Paz como conflictiva no pretende ofrecer

[226] una carga negativa al fenómeno, ya que, al fin y al cabo, son precisamente las situaciones conflictivas y las crisis que suscitan las que permiten el desarrollo de las sociedades, la academia, los partidos, las ideas y la humanidad en sí misma (Mínguez, 2015). El texto pretende, más bien, dar cuenta de las diferentes situaciones conflictivas de orden estructural y coyuntural que afronta la implementación del Acuerdo de Paz, cuya «potencia transformadora» ubica en disputa intereses de diferentes fuerzas y actores sociales. En ese orden de ideas, se hace uso de una metodología histórico-descriptiva con la intención de identificar aquellas situaciones conflictivas que afectan el proceso de implementación de los acuerdos.

La primera dimensión contempla la naturaleza misma del Estado en Colombia, que deriva en algunas de las raíces objetivas de la confrontación armada que el Acuerdo de Paz pretendió resolver. Se trata de elementos

\footnotetext{
${ }^{1}$ Esta realidad diferencia el proceso de paz colombiano de otros, como el guatemalteco, donde los actores políticos partícipes se empeñaron en imprimirle al proceso «un carácter sustantivo, con el objetivo de llegar a acuerdos que implicaran transformaciones estructurales en el país y no solamente el fin del conflicto» (CEG, 2016, p. 18).
} 
que trascienden y superan el alcance mismo del Acuerdo y cuya solución permitiría avanzar hacia la construcción de una paz estable y duradera.

Por su parte, en la dimensión coyuntural se abordan los escenarios y el peso específico de los actores políticos, acercándose a un análisis de la correlación de fuerzas de esta primera fase del proceso de implementación. En las situaciones referidas se aprecian tensiones entre las ramas del poder público, las dificultades para configurar mayorías parlamentarias a favor de la implementación al término del gobierno de Juan Manuel Santos y la dinámica social en relación con el Acuerdo de Paz, su refrendación e implementación, entre otras.

Asimismo, debe precisarse que, si bien el objetivo del presente artículo no es realizar un análisis comparado con otros procesos de paz en el mundo, Vicenç Fisas (2010) recuerda que, en todos ellos, sin excepción, solo se puede hablar de una auténtica superación de las causas que originaron los conflictos armados a partir de afrontar de forma acertada las dificultades políticas, económicas y sociales que surgen al abordar dichos asuntos estructurales. En esa misma dirección, establece que tanto los problemas que resultan comunes durante la materialización de los acuerdos, ${ }^{2}$ como los retrasos en la implementación de estos, constituyen una «extrema dificultad para el cumplimiento cabal» (Fisas, 2010, p. 22) de lo que se acuerda.

\section{Implementación conflictiva, un asunto estructural}

El proceso de implementación del Acuerdo de Paz tiene un carácter conflictivo porque en él son transversales conflictos políticos, sociales y económicos de orden estructural o propios de la formación social colombiana que desbordan los alcances del Acuerdo mismo. Esta conflictividad estructural, inherente al proceso de negociación, a la firma del Acuerdo de Paz y a la primera fase del proceso de implementación, está derivada de las características propias de conformación del Estado-nación, las cuales incluyen, por ejemplo, la incapacidad institucional de superar la inequidad de la propiedad agraria en Colombia, así como de garantizar el funcionamiento de un régimen político amplio, democrático y participativo que permita la inclusión política de fuerzas e ideas alternativas a las dominantes. Dentro de las limitaciones implícitas derivadas del proceso de construcción del Estado,

${ }^{2}$ Tales como los asuntos relacionados con la propiedad sobre la tierra, la disputa por rentas petroleras, las violaciones de derechos humanos, entre otras. 
se puede encontrar, entre otras, el monopolio ejercido sobre éste por parte la elite económica —aristocracia terrateniente- a través de la exclusión y la violencia, que lo convirtió en un asunto privado y, en consecuencia, generó un sistema político restringido que se resiste a los cambios.

De una u otra manera, el Estado colombiano y las FARC-EP, a través de la negociación y la ratificación del Acuerdo de Paz, procuraron concurrir en la solución de problemáticas derivadas de estas realidades históricas, consideradas como raíces objetivas del conflicto, y encaminados a la materialización de la paz como derecho síntesis (Salguero, 1998), considerando siempre que la implementación de los acuerdos alcanzados y la movilización transformadora de la sociedad son aspectos indisolubles a la hora de encarar un proceso de apertura política y social en Colombia.

\subsection{Configuración del Estado-nación}

El proceso de formación del Estado en Colombia determinó características que inciden en el carácter conflictivo de la implementación del Acuerdo de Paz y constituye una de las principales contradicciones de dicho proceso. Estas características están referidas a la violencia política, erigida

[228] como columna vertebral del ejercicio político, acompañada de la exclusión social y económica, la privatización del Estado por parte de una oligarquía terrateniente y el carácter confesional que uniformó a la sociedad colombiana, las cuales determinaron condiciones que configuraron un sistema político excluyente, entre otras (Urrego, 2004).

Se trata de la incapacidad que ha tenido el Estado para impulsar un proyecto verdaderamente nacional, es decir, «un proyecto político unificador, capaz de expresar en alguna medida sentimientos, lealtades e identidades comunes» (Madrigal, 2012, p. 228). Estas características estructurales fueron determinantes en la generación del conflicto y hoy forman parte de las limitaciones a superar para asumir las medidas que le pongan fin.

El proceso de independencia y la formación republicana no se tradujeron en cambios sustanciales de las condiciones de existencia de las mayorías colombianas con respecto al régimen colonial, ni en su incorporación al sistema político. La república fue sustentada en la exclusión y expropiación de los sectores sociales, considerados desde la filosofía política imperante como clase objeto de dominación, más que como sujetos de derechos: los negros, indígenas y mestizos pobres del campo y la ciudad (Carvajal, 2014). 
Esta realidad histórica de violencia, exclusión y expropiación material forma parte de las raíces del conflicto y hoy se presenta en tal multiplicidad de escenarios que sobrepasa el alcance del Acuerdo de Paz.

Desde su inicio, la conformación de una comunidad política de carácter nacional fue entorpecida por los intereses de élites regionales que hacían ilegítimos los intentos de integración social y territorial de sucesivos gobiernos incapaces de alcanzar la conducción moral de la sociedad y el monopolio de la fuerza. Esta fragmentación del poder se expresó en el plano militar durante el siglo xIx con catorce guerras civiles y veinte revoluciones locales (Uribe de Hincapié, 2001); en lo político, con la disputa por el control del aparato burocrático estatal; y en lo económico, por la pugna en el mercado entre librecambistas y proteccionistas. Tal enfrentamiento tiene como punto de inflexión la alianza al interior de una elite económica agroexportadora, ligada a la propiedad latifundista sobre la tierra y el posicionamiento de estos intereses privados, que coparon y privatizaron el espacio político público por excelencia - el Estado-, asumiendo desde entonces una estructura institucional en la que se le ha dado mayor peso al Ejecutivo, un énfasis decidido al poder central y una estrecha relación Iglesia-Estado (Cardona, 2013, noviembre 3).

La alianza en mención se estableció como bloque dominante y su fortaleza reposó en la apropiación del Estado en función de intereses particulares, de terratenientes, Iglesia católica, narcotraficantes y capital financiero internacional. Esta convivencia estructuró unas instituciones fragmentadas y funcionales a dichos intereses, de tal manera que numerosas reformas contenidas en el Acuerdo de Paz que afectan diversos escenarios de la vida económica, política y social de la nación derivaron en una respuesta y un comportamiento diferenciado a la hora de implementar lo acordado.

Dicha privatización del Estado fue acompañada de un proceso de integración social en el cual la Iglesia desempeñó un papel trascendental. Mientras el proceso de conformación del Estado-nación liberal implicó escenarios de integración social desarrollados a partir de la razón, en Colombia este proceso se desarrolló a partir de la fe. Este peso de la Iglesia en la constitución estatal es explicable por «la fuerte influencia que ésta adquirió en la identidad individual y colectiva (nacional) como doctrina uniformizante» (Madrigal, 2012, pp. 230). 
Esta influencia de la Iglesia católica desembocó en la generación de un sistema político restringido, basado en una «voluntad general» construida a partir de «dogmas necesarios para realizar los deberes sociales y morales de la República Cristiana» (Madrigal, 2012, pp. 232), no de la república democrática. De esta forma, se construyó un Estado cuyo control ideológico se sustentó en el desprendimiento de los individuos por el interés público y en la ausencia de un análisis crítico racional de sus condiciones materiales de vida, realidades objetivas que configuraron en la sociedad una cultura política resistente a dinámicas de reconciliación, modernización y paz, pretendida con la implementación del Acuerdo de Paz (Madrigal, 2012).

Con ocasión de esta realidad, la mayoría de la sociedad que afrontó el fin del conflicto con las FARC-EP y el Acuerdo de Paz tiene un fuerte arraigo confesional, y los opositores al Acuerdo encontraron en esta realidad terreno fértil para la propaganda en contra de lo pactado, a partir de un discurso que alertaba sobre supuestos contenidos inmorales en relación con la «ideología de género», los valores de la familia, entre otras. Se trata de una sociedad y un Estado rígidos y reticentes al cambio.

Así, el Estado asume la dirección política de la sociedad o, en otras [230] palabras, le impone los intereses de «la clase económicamente dominante o de los sectores dominantes dentro de las clases hegemónicas» (García, 2012, p. 220), en el caso colombiano, los de la gran propiedad terrateniente que han monopolizado históricamente sus funciones. Esto se refleja, por ejemplo, en la persistente resistencia a la implementación de la Reforma Rural Integral planteada en el Acuerdo de Paz, así como las posibilidades de ampliación del sistema político excluyente.

De otra parte, el Estado colombiano mantuvo una relativa cohesión en torno a la voluntad de sostener la guerra durante muchos años, mientras que dicha armonía y articulación pareció difuminarse a la hora de comprometerse con la implementación de la paz, como consecuencia de las divergencias profundas al interior del Estado en la forma como se concibe, se interpreta y se aplica la política de paz. Estas divergencias están asociadas a contradicciones latentes al interior del aparato estatal, contradicciones que, en sectores ligados históricamente, no son antagónicas, pero que se manifiestan en coyunturas específicas como las presentadas en el proceso de implementación del Acuerdo de Paz entre el Estado y las FARC-EP. 
La cohesión durante años frente a la guerra le permitió al bloque dominante mantener y consolidar el proyecto de Estado, por esta razón la potencia transformadora del Acuerdo de Paz, que implica el fin de la confrontación armada, genera una reacción fragmentada en el bloque dominante, en tanto supone la alteración de realidades que han beneficiado a los sectores que conforman la alianza.

Como consecuencia de esta realidad histórica, el proceso de implementación del Acuerdo de Paz alcanzado entre el Estado colombiano y las FARC-EP ha afrontado múltiples dificultades, tales como una sociedad apática, producto del predominio del interés particular sobre el general, estimulado durante la conformación del Estado; el predominio en la cultura política de hacer uso de la violencia y de la eliminación física de los opositores; la imposibilidad del Estado para garantizar y ejercer el monopolio legítimo de la violencia; y su incapacidad para resolver el problema estructural de la tierra en Colombia que, entre otras, develan algunas de las dificultades y conflictos estructurales que afronta la implementación del Acuerdo de Paz.

Estos elementos del proceso de conformación estatal que definen la naturaleza, las características y la estructura misma del Estado tienen hondas repercusiones en la implementación del Acuerdo de Paz. Entre ellas, es preciso resaltar las siguientes: la privatización del Estado, puesto al servicio de la aristocracia terrateniente reacia a implementar las reformas contenidas en el Acuerdo, particularmente la Reforma Rural Integral (RRI); un sistema político restringido que no alienta la participación ciudadana en la búsqueda de la paz, ni garantiza una apertura democrática; una fragmentación institucional reflejada en la incapacidad del Estado de garantizar coherencia entre las ramas del poder público para el cumplimiento de un acuerdo que lo compromete en su conjunto; y la estructuración de una cultura política ajena al interés común y colectivo, el cual genera un desprendimiento y desinterés social y que redundan en la implementación conflictiva de lo acordado.

Como ya se mencionó, la configuración del Estado en Colombia se ha caracterizado por la hegemonía de los sectores ligados a la gran propiedad sobre la tierra, fenómeno que ha restringido la implementación de reformas agrarias que han tenido como común denominador no haber afectado significativamente la estructura de esta propiedad. En este sentido, merece la pena recordar que el conflicto armado interno, del que son protagonistas 
—entre otros - las guerrillas revolucionarias y el Estado, tuvo su origen, precisamente, en la inequitativa estructura agraria heredada del régimen colonial. Pese a que esta realidad es reconocida, la evaluación del proceso de implementación de lo acordado entre las FARC-EP y el Gobierno colombiano, referido a la Reforma Rural Integral es precario. ${ }^{3}$ De acuerdo al informe de evaluación presentado por el Instituto Kroc (2017) de la Universidad de Notre Dame, la implementación referida a la reforma rural integral y la solución al problema de drogas ilícitas son los aspectos más atrasados en este momento. Esta realidad no ha sido superada en Colombia, ni asumida dentro de las reformas propias de las revoluciones democrático-burguesas como consecuencia del peso político mantenido por los grandes dueños de la tierra que han hegemonizado históricamente el bloque dominante.

Teniendo en cuenta estos elementos, es previsible que los cacicazgos regionales conformen alianzas entre sectores económicos y políticos a quienes no son provechosas las reformas contenidas en el Acuerdo de Paz y cuya implementación tiene un «enfoque territorial», derivando en una férrea oposición a los acuerdos y la imposición de un ambiente conflictivo. Las razones para esto son de diversa índole: la implementación del Acuerdo de Paz contrae implicaciones penales y jurídicas a diversos sectores ligados con el despojo de tierras; amplía la participación y crea nuevas circunscripciones electorales que podrían afectar negativamente los caudales electorales de las élites y redes regionales creadas en torno a la estructura de propiedad sobre la tierra; $y$ afecta directamente el funcionamiento de economías ilegales que «aceitan» las maquinarias, burocracias y alianzas políticas y económicas tradicionales en los territorios.

\section{Aproximación a la coyuntura de una implementación conflictiva}

En este apartado se analizan los fenómenos o elementos de orden coyuntural que incidieron en el primer año de implementación del Acuerdo

\footnotetext{
${ }^{3}$ En este sentido, es significativa la relevancia que se otorgó a la transformación de la estructura agraria como garantía de bienestar de la población, en procesos de paz como el guatemalteco. Así, el punto $27 \mathrm{del}$ Acuerdo sobre aspectos socioeconómicos y cuestión agraria estipula que «la transformación de la estructura de la tenencia y el uso de la tierra debe tener como objetivo la incorporación de la población rural al desarrollo económico, social y político, a fin de que la tierra constituya para quienes la trabajan, base de su estabilidad económica, fundamento de su progresivo bienestar social y garantía de su libertad y dignidad» (CEG, 2016).
} 
de Paz y en los resultados que durante el primer año arrojó la implementación. Para lo cual se asume que en el marco de la implementación del Acuerdo se enfrentan intereses sensibles de actores protagónicos en la escena nacional actual y en el proceso de conformación del Estado en Colombia; a su vez, se entiende que una coyuntura hace referencia a la relación o a la correlación de fuerzas entre diferentes actores en un determinado momento histórico. Es por esto que, una vez analizadas las condiciones estructurales que afectaron la implementación de los acuerdos, es pertinente dar una mirada a algunos de los factores.

\subsection{Refrendación del Acuerdo: inicio de una implementación conflictiva}

Si bien el Acuerdo de Paz firmado en Cartagena el 26 de septiembre de 2016 expuso la voluntad de las partes para pactar el fin de la guerra, también inauguró una implementación de carácter conflictivo. Así lo reveló la fuerte discusión entre las partes y entre diversos actores de la política nacional sobre el mecanismo idóneo para la refrendación del Acuerdo y los resultados mismos de su aplicación.

Las posiciones expresadas en la opinión pública, las fuerzas políticas y las partes en conversación oscilaban desde la necesidad de hacer una asamblea nacional constituyente, hasta no someter lo acordado a refrendación popular o activar uno de los mecanismos de participación ciudadana contemplados en la Constitución Política de 1991. En la primera de las posturas mencionadas se encontraban las FARC-EP, que insistían en convocar a una asamblea nacional constituyente, argumentando la necesidad de realizar un gran pacto político nacional que cerrara el conflicto armado y les diera a los acuerdos alcanzados rango constitucional. En la otra orilla se encontraba el Gobierno colombiano, sosteniendo que una asamblea constituyente no era el mecanismo idóneo para la refrendación, pues los acuerdos no buscaban cambiar estructuralmente el modelo económico o la estructura del Estado, y que por ello se inclinaba por una figura como el plebiscito, revelando el conflicto latente entre las partes a través de esta contradicción. Eso sí, desde un comienzo el Gobierno fue inamovible en la intención de someter lo acordado a la votación de los ciudadanos, situación en la que también distaban de las FARC-EP, quienes planteaban que el derecho a la paz no debía ser sometido a consideración. 
Las FARC-EP y otras voces nacionales como el entonces fiscal general de la Nación, Eduardo Montealegre, plantearon como innecesaria la medida de someter a votación el Acuerdo de Paz e invitaron al Gobierno a hacer uso de sus facultades especiales — Congreso de la República— para garantizar el cumplimiento del «derecho síntesis». Finalmente, el Gobierno tomó la decisión unilateral de convocar a un plebiscito como mecanismo de refrendación —medida que las FARC-EP señaló en su momento como una imposición-. Este último es un mecanismo consagrado en el artículo 103 de la Constitución Política de 1991 y desarrollado por la Ley 134 de 1994 en sus artículos 77-80. La Corte Constitucional en su Sentencia C-379 declaró exequible la realización del plebiscito, dando paso a la convocatoria a los colombianos para votar aprobando o no los acuerdos suscritos entre el Gobierno y las FARC-EP. Es de resaltar que la Corte dio luz verde al «cambio de umbral» de aprobación igual o superior a 13\% del censo electoral.

Esta disputa entre los diferentes actores partícipes de las discusiones por determinar el mecanismo de refrendación se vio potenciada por un profundo desconocimiento de los acuerdos por parte de la sociedad, así como por el bajo nivel educativo, técnico y científico (El Tiempo, 2017, abril 20) que ha afectado históricamente a la gran mayoría de población colombiana, «Un país en el que 3 de cada mil personas saben leer de manera crítica no se mueve por las ideas, sino por emociones primarias como el miedo, la ira o la venganza» (De Zubiría, 2016, junio 10), dejando en la mesa uno de los principales factores que afectaron el resultado de la votación del plebiscito: la crisis educativa. No es un secreto que Colombia es uno de los países con mayor déficit educativo, tanto en su calidad como cobertura; sin embargo, esta desatención por parte del Estado ha sido funcional y utilizada a favor de ciertos sectores que han forjado su discurso político apalancado en el desconocimiento, la desinformación y la vulnerabilidad social y económica de los colombianos. Esta amalgama de condiciones fue caldo de cultivo para los sectores que se oponían a la aprobación de los acuerdos, partiendo de que Colombia es un país que:

Anclado en el pasado. No quiere justicia, sino venganza. No quiere reparación, sino cárcel. No quiere comprensión, sino que destila odio. Es claramente la población a la cual el Uribismo le dirigió su mensaje; y por ello, fue presa fácil de un discurso muy sencillo y repetitivo, lleno de falacias, mentiras y de verdades a medias, que tenía como propósito incitar el odio, la ira y la venganza, los combustibles principales en todas las confrontaciones (De Zubiría, 2016, junio 10). 
Elementos estructurales y coyunturales de una implementación conflictiva del Acuerdo...

Es de esta manera que por medio de una campaña desinformativa construida a partir de la movilización de «miedos», la derecha y extrema derecha colombiana lograron influenciar a un amplio sector de la población para rechazar en las urnas los acuerdos de La Habana. ${ }^{4}$ Es de resaltar que la sección quinta del Consejo de Estado (radicado 11001-03-28-000-201600081-00) señaló que:

Emerge con meridiana claridad que la información que se suministró al electorado en la fase definitiva de campaña reflejó una total tergiversación, en muchos de sus aspectos neurálgicos, del contenido del acuerdo sometido a votación el 2 de octubre de 2016, el cual fue determinante para la obtención del resultado en dicha contienda electoral, comoquiera que la manera sistemática y masiva en la que se llevaron a cabo las diferentes campañas generó una influencia global que torna imposible determinar con claridad la voluntad de los sufragantes.

De ahí que se concluya la existencia de un engaño generalizado que anuló la libertad del electorado para escoger autónomamente entre las opciones existentes frente al plebiscito en cuestión, dejando en evidencia la estrategia de dichos sectores para atacar lo acordado (Semana, 2016, diciembre 19).

La conflictividad emergente del triunfo del No (Hernández, 2017) se expresó en al menos tres escenarios diferentes durante el primer año de implementación del Acuerdo de Paz. En primer lugar, se impidió que los compromisos adquiridos por el gobierno de Juan Manuel Santos y las FARCEP fueran integrados al bloque de constitucionalidad; en segundo lugar, las partes se vieron obligadas a ajustar y modificar elementos del Acuerdo según los requerimientos del bloque ganador en el plebiscito (Semana, 2016, marzo 10); y en tercer lugar, ambientó políticamente el país para que posteriormente fuera restringido parcialmente el Acto Legislativo 1 de 2016 que reglamentaba el Procedimiento Legislativo Especial para la Paz. Dicha coyuntura estuvo marcada por una correlación de fuerzas favorable a los sectores opositores al Acuerdo de Paz, situación que configuró un contexto conflictivo para la implementación.

\footnotetext{
${ }^{4}$ Situación que, como en el caso guatemalteco (1996), no afectó el proceso de desarme de la insurgencia, pues en ambos procesos hubo claridad en no condicionar «su desarme y desmovilización a que se refrendaran los acuerdos de paz» (Nasi, 2015, marzo 22).
} 


\subsection{El rol del Poder Judicial}

El papel de la rama judicial es determinante en la implementación del Acuerdo de Paz, entre otras, porque en la Corte Constitucional recae la responsabilidad de hacer control de constitucionalidad a las normas aprobadas para la implementación de la paz y porque en los jueces de ejecución de penas recae el cumplimiento efectivo de la amnistía otorgada a los excombatientes de las FARC-EP privados de la libertad, a través de la Ley 1820 de 2016. Los sectores opositores a los acuerdos encontraron en la rama judicial un aliado que, si bien no les permitiría deshacer lo acordado vía sentencia, eventualmente les abrió un escenario propicio para tal tarea: las votaciones ya no serían en bloque, además de tener potestad de modificar lo acordado por parte del Legislativo.

En ese sentido, merece la pena anotar que desde el momento en que las FARC-EP iniciaron el proceso de dejación individual de las armas la Corte Constitucional modificó la tramitación expedita en el Congreso del andamiaje jurídico en el que está sustentado el Acuerdo de Paz y el impulso de políticas públicas indispensables para el logro de la paz. Según el criterio expuesto por las FARC, con las medidas adoptadas por la Corte se sembró «la mayor [236] de las incertidumbres, respecto a la disposición y capacidad del Estado en todos sus poderes para honrar lo pactado en La Habana» (El País, 2017, mayo 18). Dicha incertidumbre es alimentada por las disposiciones promulgadas en marzo de 2017, cuando luego de cuatro meses de «implementación de los acuerdos de paz» —estando las FARC-EP en los puntos de concentración y en proceso de desarme- la Corte Constitucional respondió una demanda de inconstitucionalidad radicada por varios senadores uribistas contra el Acto Legislativo 1 de 2016, planteando en el cuerpo de la demanda que «con estos apartes del Acto Legislativo 1 se vulneraban las facultades del Congreso y las normas establecidas en la Constitución Política» (El País, 2017, mayo 18).

La restricción al Acto Legislativo por parte de la Corte Constitucional fue un hecho determinante en una serie de comportamientos de la rama judicial que, en su conjunto, incidieron en el desarrollo conflictivo de la implementación del Acuerdo de Paz en su primera etapa. La Corte Constitucional les dio razón parcial a los demandantes y, como resultado, todas las iniciativas legislativas quedaron sujetas a las proposiciones modificatorias de cualquier congresista. Es decir, nada más ni nada menos que le dio la facultad al Congreso de modificar los marcos normativos de lo acordado en 
La Habana. Esta situación sometió la implementación del Acuerdo de Paz y el cumplimiento del calendario normativo al sabotaje parlamentario de buena parte del congreso, permitiendo la eliminación y adición de elementos al temario, convirtiendo el Congreso en un escenario donde primaron intereses políticos y de clase por sobre los acuerdos de paz alcanzados.

En esa dirección, merece la pena también resaltar la paquidérmica actitud de la rama judicial, y concretamente de los jueces de ejecución de penas, para cumplir con la Ley 1820 de 2016 que garantiza la libertad a los combatientes de las FARC-EP detenidos en las cárceles y que fueron favorecidos por la Ley de Amnistía producto del Acuerdo de Paz Esta actitud adoptada por parte de la rama judicial, en cabeza de la Corte Constitucional, desencadenó lo que posteriormente fue un nuevo escenario de confrontación entre las FARC-EP, el Gobierno nacional y aquellos sectores empecinados en torpedear el Acuerdo de Paz, ralentizando el proceso, abriendo nuevos debates y creando incertidumbre sobre lo pactado en La Habana.

Más allá de la división de poderes públicos, la paz como derecho síntesis que podría materializarse a través del Acuerdo de Paz debió comprometer a todas las instituciones del Estado, teniendo en cuenta que la Constitución Política establece que uno de los mandatos en el marco de los derechos fundamentales es el logro de la paz como un derecho y un deber inalienable de los colombianos (artículo 22), los cuales deberán propender por su logro y mantenimiento (artículo 98), y en esa medida, también una tarea prioritaria del Estado en su calidad de garante constitucional.

\subsection{Gobierno y Parlamento. ¿Voluntad política y cohesión de Estado?}

Una vez se determinó por parte de la Corte Constitucional el alcance del Acto legislativo 1 de 2016 y el consecuente papel que desempeñaría el Congreso en la materialización del articulado del Acuerdo de Paz, el Ejecutivo, en cabeza de Juan Manuel Santos, y el Congreso protagonizaron el incumplimiento y conflictividad en la implementación. En ese sentido, el carácter conflictivo de la implementación se ha alimentado, entre otras, por la desidia del Estado, que no cumplió a cabalidad con sus funciones respecto al proceso de paz. Si bien es cierto que cumplió el propósito elemental de Estado, desarmar a las FARC-EP, no ha sido capaz de supervisar la implementación del Acuerdo de Paz, ni de generar un consenso favorable 
en la sociedad hacia la reconciliación. A pesar de esto, la implementación dio inició con la concentración y el proceso de desarme de las FARC-EP. ${ }^{5}$ En ese momento se instauró la Comisión de Seguimiento Impulso y Verificación a la Implementación del Acuerdo Final (CSIVI). Dicha entidad está integrada por tres delegados de alto nivel de las partes — Gobierno y las FARC-EPque tiene por tarea, como su nombre lo indica, hacer el seguimiento a la implementación de la totalidad del Acuerdo. En teoría, parte de su misión durante el procedimiento legislativo especial para la paz era discutir y construir sobre criterios técnicos los proyectos de ley que el Gobierno debe presentar relacionados con la implementación del Acuerdo de Paz. Se plantea «en teoría» porque las FARC-EP han denunciado en reiteradas ocasiones que el Gobierno Nacional ha presentado diversos proyectos de ley sin conciliar su contenido en la CSIVI, contrario a lo estipulado en el Acuerdo de Paz. Esta situación revela una vez más el carácter conflictivo de la implementación, no solo porque representa una violación al numeral 6.1 del Acuerdo de Paz relacionado con la buena fe entre las partes, sino porque revela la incapacidad y falta de iniciativa del Gobierno para acompasar los tiempos y trámites legislativos, con la elaboración de proyectos de ley consensuados en la CSIVI y previamente definidos como prioritarios en el calendario de implementación del punto 6 del Acuerdo.

Por otra parte, el Parlamento se convirtió en uno de los principales obstáculos para la implementación, anteponiendo las agendas e intereses propios de los partidos políticos, desconociendo lo acordado y torpedeando sustancialmente el espíritu de los acuerdos. A pesar de que durante la etapa de negociaciones del Acuerdo y en el inicio del fast track, la gran mayoría de los partidos estuvieron alineados en la denominada Unidad Nacional, también hubo sectores políticos que se opusieron férreamente, tanto a las negociaciones como a la implementación normativa en el Congreso.

Debe agregarse que la dinámica de los partidos políticos que conformaban la Unidad Nacional y el bloque parlamentario que apoyaba

\footnotetext{
${ }^{5}$ En Colombia, la dejación y desmonte de la estructura militar de las FARC-EP fue un proceso completado rápidamente, comparado con otros procesos exitosos como los de El Salvador, Guatemala y Mozambique. Las zonas de concentración establecidas en el Acuerdo de Paz fueron habitadas a los tres meses de iniciado el proceso por $70 \%$ de los combatientes. En contraste, en El Salvador el FMLN tardó cerca de diez meses para concentrar $60 \%$ de sus fuerzas; en Guatemala, la URNG tardó cinco meses después de la firma del acuerdo; en Mozambique, catorce meses después de la firma del acuerdo solo $20 \%$ de los combatientes asumieron la concentración previa a la desmovilización (Instituto Kroc, 2017).
} 
los Acuerdos de Paz cambió. La correlación de fuerzas se volvió desfavorable frente a la implementación del Acuerdo en la medida en que el periodo presidencial agotaba su ciclo, en que se iniciaba un nuevo periodo electoral y en que los intereses partidarios prevalecían. Muestra de ello es cómo el entonces vicepresidente de la República, Germán Vargas Lleras, jefe natural del partido Cambio Radical, que durante las negociaciones se pronunció de manera somera y tímida respaldando la mesa, propició un cambio de posición de su partido en el Senado, llegando incluso a obstaculizar varios de los acuerdos centrales de la negociación luego de presentar su renuncia al Gabinete; así como también la férrea oposición de Rodrigo Lara, presidente de la Cámara de Representantes y miembro del mismo partido, a la aprobación de la Reforma Política, indispensable en el proceso de apertura política y democratización de la sociedad colombiana.

Es importante señalar que entre los acuerdos que no fueron implementados normativamente a través del Procedimiento Legislativo Especial para la Paz se encuentra la Reforma Política, la cual fue ampliamente debatida en el punto 2, participación política, en la Mesa de Negociaciones de La Habana y pretendía:

[...] una ampliación democrática que permita que surjan nuevas fuerzas en el escenario político para enriquecer el debate y la deliberación alrededor de los grandes problemas nacionales y, de esa manera, fortalecer el pluralismo y por tanto la representación de las diferentes visiones e intereses de la sociedad, con las debidas garantías para la participación y la inclusión política (Gobierno y FARC-EP, 24 de noviembre de 2016, p. 30).

Dicha reforma fue hundida por varios factores, en lo fundamental, por los sustanciales cambios presentados en su articulado que hicieron perder el sentido y espíritu de lo pactado en La Habana, así como por la dificultad para alcanzar mayorías durante las votaciones.

En el mismo sentido, otro de los incumplimientos en el marco legislativo y de implementación fue el hundimiento de las dieciséis circunscripciones especiales para la paz, las cuales buscaban ser una de las principales garantías para las víctimas del conflicto en el marco de la participación política. Esto se debió al ausentismo del Partido de la $U$-partido del entonces presidente Santos-y del Partido Liberal, así como a la oposición del Centro Democrático, del Partido Conservador y del partido Cambio 
Radical — partido del ya entonces candidato a la presidencia Germán Vargas Lleras-. Pese a que la Reforma Política y las Circunscripciones Transitorias Especiales de Paz representaban un interés de Estado, en cuanto se acordó su necesidad en los Acuerdos de Paz, terminaron diluidas en los intereses sectoriales y económicos de las maquinarias políticas que se verían afectadas, y que hoy ocupan las mayorías en el Parlamento.

De esta manera, se puede afirmar que, en el contexto de la implementación normativa — fast track-, el Ejecutivo y el Legislativo no fueron coherentes con el espíritu y alcances del Acuerdo de Paz; por el contrario, se erigieron como los principales obstáculos a la hora de cumplir con los elementos mínimos programados y concertados para proceder según lo previsto en el Acuerdo en materia de implementación, verificación y seguimiento. Lo concreto es que a un año de la firma de los Acuerdos y de iniciado el proceso de implementación, «de los 20 proyectos de ley y acto legislativo presentados por el Gobierno para desarrollar los puntos pactados con las FARC, sólo se han aprobado siete» (Cáritas, 2017, noviembre 28).

\section{Conclusiones}

[240] La implementación del Acuerdo de Paz entre el Gobierno y las FARC-EP se erige como un nuevo escenario en el que tiene continuidad el conflicto político, económico y social que no ha sido resuelto, un espacio de confrontación que entremezcla contradicciones de carácter estructural que emergen en la coyuntura y que se evidencian fundamentalmente en la falta de voluntad política del Estado colombiano — cooptado históricamente por intereses privados - para concretar lo pactado con las FARC-EP.

A pesar de que el acuerdo que se busca implementar no garantiza la superación de las causas estructurales que alimentaron el conflicto, el proceso de implementación de lo pactado se ha convertido en una caja de pandora que ha propiciado un proceso de profunda polarización política. Ciertamente, en Colombia existe un sector social, asociado a la gran propiedad sobre la tierra, que parece desear que el proceso de implementación de lo acordado no se materialice, pues no es funcional al proceso de acumulación por desposesión adelantado por décadas en Colombia, desconociendo que «es necesario emprender reformas estructurales que hagan posible la construcción de una paz de calidad» (Instituto Kroc, 2017) si es que no se desea perpetuar las causas objetivas del conflicto armado. 
Uno de los factores relevantes, de cara a la conflictividad presentada en esta primera fase de la implementación, es el nivel diferenciado de compromiso político que han tenido los actores con la misma. En esa dirección, se identifica un alto nivel de diligencia entre las partes para abordar los asuntos de desarme y concentración, pero poco de cumplimiento del Estado en cuanto a los demás compromisos adquiridos con el Acuerdo de Paz.

Para la comunidad internacional que acompañó el proceso, las FARC-EP cumplieron: desmontaron su estructura militar, hicieron dejación de las armas y hoy son un partido que desarrolla una vida política legal. ${ }^{6}$ En contraparte, al Estado colombiano le ha faltado cohesión política para la implementación de la paz y parece ser que su obsesión no es la solución política, con todo lo que ello implica, sino el desarme de la guerrilla. Esta sensación se alimenta y refuerza por la manera como se ha intentado torpedear el funcionamiento y las competencias de la Jurisdicción Especial para la Paz (JEP), poniendo en tela de juicio la seguridad jurídica de los excombatientes y la reconstrucción de un asunto estructural para el conflicto colombiano: la verdad.

Finalmente, se encuentra un actor que no ha asumido el protagonismo que le corresponde, el conjunto social colombiano, marginado de las preocupaciones públicas y marcado por una cultura confesional, carente de espíritu crítico, que en su mayoría se mantiene expectante, en un estado de imperturbabilidad. Esta actitud no es otra cosa que el reflejo de un proyecto «nacional» que ha cimentado en los colombianos «una identidad débil, una baja autoestima, un orgullo vacío y una dignidad vacua» (Rincón, 2015, julio 5). La superación del conflicto político, social y armado en Colombia, «más allá del acuerdo, del decreto, de la norma y de la ley, [requiere] un cambio profundo en la conciencia colectiva» (Gómez, 2017, junio 20). El problema en la coyuntura no es que el Estado y la sociedad le incumplan a las FARC, lo trascendental es que con esta actitud y en este marco social y político se le hereda a las próximas generaciones de colombianos un conflicto potenciado, que será necesario resolver para el logro del buen vivir nacional.

\section{Referencias bibliográficas}

1. Cardona Alzate, Jorge. (2013, noviembre 3). El legado de los liberales radicales del siglo xIx. El Espectador. Recuperado de https:/www.elespectador.com/noticias/ politica/el-legado-de-los-liberales-radicales-del-siglo-xix-articulo-456407

${ }^{6}$ El 6 de octubre de 2017 finalizó la dejación de armas y la entrega de 69034 kilogramos de armamento y munición por parte de las FARC a la ONU (Cáritas, 2017, noviembre 28). 
2. Carvajal Hernández, Diana. (2014). Violencia y Nación en Colombia: de la Nación homogénea a Nación multicultural. Revista Eleuthera, 11, pp. 101-126. Recuperado de http://eleuthera.ucaldas.edu.co/downloads/Eleuthera11_7.pdf

3. Centro de Estudios de Guatemala (CEG). (2016). Proceso de paz en Guatemala: un estudio de caso sobre la negociación y el proceso de diálogo nacional en Guatemala. Recuperado de https://www.swisspeace.ch/fileadmin/user_upload/pdf/ Mediation/Estudio_de_caso_sobre_Proceso_de_paz_en_Guatemala.pdf

4. Colombia. Asamblea Nacional Constituyente. Constitución Política. (20 de julio de 1991). Recuperado de http://www.secretariasenado.gov.co/senado/basedoc/ constitucion_politica_1991.html

5. Colombia. Congreso de la República. Ley 134. (31 de mayo de 1994). Por la cual se dictan normas sobre mecanismos de participación ciudadana. Recuperado de http://www.secretariasenado.gov.co/senado/basedoc/ley_0134_1994.html

6. Colombia. Congreso de la República. Acto Legislativo 1. (7 de julio de 2016). Por medio del cual se establecen instrumentos jurídicos para facilitar y asegurar la implementación y el desarrollo normativo del acuerdo final para la terminación del conflicto y la construcción de una paz estable y duradera. Recuperado de http://www. secretariasenado.gov.co/senado/basedoc/acto_legislativo_01_2016.html

7. Colombia. Congreso de la República. Ley 1820. (30 de diciembre 2016). Por medio de la cual se dictan disposiciones sobre amnistía, indulto y tratamientos penales especiales y otras disposiciones. Recuperado de http://es.presidencia.gov. co/normativa/normativa/LEY\% 201820\%20DEL \% 2030\% 20DE\%20DICIEMBRE $\% 20$ DE\%202016.pdf

8. Colombia. Consejo de Estado. Radicación 11001-03-28-000-2016-00081-00. (19 de diciembre de 2016). Nulidad Electoral. Auto que admite la demanda y resuelve sobre la solicitud de medidas cautelares. Recuperado de http://consejodeestado.gov. co/documentos/sentencias/19-12-2016_11001032800020160008100.pdf

9. Colombia. Corte Constitucional. Sentencia C-379. (18 de julio de 2016). Recuperado de http://www.corteconstitucional.gov.co/relatoria/2016/c-379-16.htm

10. De Zubiría, Julián. (2016, junio 10). El triunfo del NO y el fracaso de la educación colombiana. Semana. Recuperado de https://www.semana.com/educacion/ articulo/implicaciones-del-no/497863

11. El País. (2017, mayo 18). «Proceso de paz vive ahora la situación más adversa de todas» Farc. Recuperado de http://www.elpais.com.co/proceso-de-paz/proceso-depaz-vive-ahora-la-situacion-mas-adversa-de-todas-farc.html

12. El Tiempo. (2017, abril 20). Ministerio de Educación rindió cuentas. Recuperado de http://www.eltiempo.com/vida/educacion/rendicion-de-cuentas-delministerio-de-educacion-nacional-79810

13. Fisas, Vicenç. (2010). Introducción a los procesos de paz. Quaderns de Construcció de Pau. Escola de Cultura de Pau. Recuperado de https://escolapau.uab. cat/img/qcp/introduccion_procesos_paz.pdf 
Elementos estructurales y coyunturales de una implementación conflictiva del Acuerdo...

14. García Villegas, Mauricio (dir). (2012), Jueces sin Estado. La justicia colombiana en zonas de conflicto armado. Bogotá, D. F.: Siglo del Hombre, Dejusticia, Fundación Konrad Adenauer.

15. Gobierno de Colombia y FARC-EP. (24 de noviembre de 2016). Acuerdo final para la terminación del conflicto y la construcción de una paz estable y duradera. Alto Comisionado para la Paz. Recuperado de http://www.altocomisionadoparalapaz. gov.co/procesos-y-conversaciones/Documentos \% 20compartidos/24-112016NuevoAcuerdoFinal.pdf

16. Gómez Lara, Federico. (2017, junio 20). Nos falta mucho todavía... Semana. Recuperado de http://www.semana.com/opinion/articulo/colombia-no-estapreparada-para-la-paz/529202

17. Hernández Pérez, Mauricio. (2017). El triunfo del No: la paradoja emocional detrás del plebiscito. Revista Ciudad Paz-ando, 10 (2), pp. 92-96. https://doi. org/10.14483/2422278X.12218

18. Instituto Kroc de Estudios Internacionales de Paz. (2017). Informe sobre el estado efectivo de implementación del acuerdo de paz en Colombia. Recuperado de https:/www.utp.edu.co/cms-utp/data/bin/UTP/web/uploads/media/comunicaciones/ documentos/Informe-Kroc-final.pdf

19. Madrigal Garzón, Alexander. (2012) La formación del Estado-nación en Colombia durante el siglo xIx: el trazado histórico-social de la institución del orden político. Perspectivas Internacionales, 8 (1), pp. 219-235. Recuperado de http://revistas. javerianacali.edu.co/index.php/perspectivasinternacionales/article/view/845/1370

20. Mínguez Alcaide, Xavier. (2015). Conflicto y paz en Colombia. Significados en organizaciones defensoras de los derechos humanos. Revista de Paz y Conflictos, 8 (1). pp. 179-196.

21. Nasi, Carlo. (2015, marzo 22). Refrendación del acuerdo de paz: las razones, las ventajas y los riesgos. Razón Pública. Recuperado de https://www.razonpublica. com/index.php/conflicto-drogas-y-paz-temas-30/8343-refrendaci\% C3\% B3n-delacuerdo-de-paz-las-razones,-las-ventajas-y-los-riesgos.html

22. Pastoral Social Cáritas Colombiana. (2017, noviembre 28). Avances en la implementación del proceso de paz. Recuperado de http://caritascolombiana.org/ pastoral-social-realiza-seguimiento-a-la-implementacion-de-los-acuerdos-de-paz/

23. Rincón, Omar. (2015, julio 5). La baja autoestima de los colombianos. Razón Pública. Recuperado de https://www.razonpublica.com/index.php/cultura/8565-labaja-autoestima-de-los-colombianos.html

24. Salguero Salvador, Geovani. (1998). Hacia la consolidación del derecho humano a la paz. Relaciones Internacionales, 7 (15). Recuperado de https://revistas. unlp.edu.ar/RRII-IRI/article/view/1767

25. Semana. (2016, marzo 10). Renegociar el acuerdo de paz: ¿Es posible? Recuperado de https://www.semana.com/nacion/articulo/plebiscito-para-la-paz-serao-no-posible-renegociar-los-acuerdos/496759 
26. Semana. (2016, diciembre 19). Consejo de Estado dice que hubo «engaño generalizado» en campaña del No en el Plebiscito. Recuperado de http://www.semana. $\mathrm{com} /$ nacion/articulo/consejo-de-estado-reconoce-que-hubo-engano-generalizado-encampana-del-no-al-plebiscito/510010

27. Uribe de Hincapié, María Teresa. (2001). Las guerras por la nación en Colombia durante el siglo xIx. Estudios Políticos, 18, pp. 9-27. Recuperado de http:// aprendeenlinea.udea.edu.co/revistas/index.php/estudiospoliticos/article/view/17426

28. Urrego, Miguel Ángel. (2004). Crisis del Estado nacional en Colombia. Una perspectiva histórica. Michoacán: Universidad Michoacana de San Nicolás de Hidalgo. 